\title{
Evidence against the hypothesis that BCL-2 inhibits apoptosis through an anti-oxidant effect
}

\author{
Agnes Gardner ${ }^{1}$, Feng-Hao $\mathrm{Xu}^{1}$, Catherine Fady ${ }^{1}$, \\ Theodore Sarafian ${ }^{2}$, Yiping $\mathrm{Tu}^{1}$ and Alan Lichtenstein ${ }^{1,3}$ \\ 1 Department of Medicine, VA West Los Angeles Hospital-UCLA Medical Center, \\ Los Angeles, California, USA \\ 2 Department of Pathology, UCLA Medical School, Los Angeles, California, USA \\ 3 corresponding author: Alan Lichtenstein, MD, Hematology-Oncology, VA West \\ Los Angeles Hospital, W111H, 11301 Wilshire Blvd, Los Angeles, California \\ 90073. tel: (310) 268-3622; fax: (310) 268-4908
}

Received 13.8.96; revised 27.1.97, accepted 8.4.97

Edited by C.J.Thiele

\begin{abstract}
We contrasted possible protection against apoptosis afforded by either BCL-2 expression or anti-oxidant inhibitors in the same tumor target challenged by two distinct triggers of apoptosis. Exposure of L929 fibroblasts to tumor necrosis factor (TNF) or etoposide (VP-16) induced apoptotic death with similar kinetics. Enforced expression of BCL-2 significantly protected against apoptosis induced by VP-16 but had no effect against TNF-induced apoptosis. In contrast, the antioxidants desferrioxamine, butylated hydroxyanisol and $\mathrm{N}$ acetyl cysteine all inhibited TNF-induced apoptosis in a concentration-dependent fashion. Although exposure to VP16 resulted in a significant generation of intracellular oxyradicals, the above three anti-oxidant inhibitors had no effect on VP-16-induced apoptotic death. Interestingly, enforced expression of BCL-2 also inhibited the ability of VP-16 to generate oxy-radicals and to depress intracellular glutathione levels. These results indicate that BCL-2 can exert anti-oxidant effects but argue against the hypothesis that these effects are critical to its protection against apoptosis.
\end{abstract}

Keywords: anti-oxidants, TNF, BCL-2, VP-16

Abbreviations: TNF, tumor necrosis factor; $\mathrm{ROI}$, reactive oxidant intermediate; BHA, butylated hydroxyanisol; NAC, Nacetyl cysteine; DCF, dichloro fluorescence; $M C B$, monochlorobimane; $\mathrm{PLA}_{2}$, phospholipase $\mathrm{A}_{2}$

\section{Introduction}

Expression of the BCL-2 oncoprotein protects against apoptotic cell death induced by many different types of stimuli. The mechanism by which BCL-2 protects is still unclear. Two previous studies (Kane et al, 1993; Hockenbery et al, 1993) suggested that BCL-2's function as a survival factor was mediated through an anti-oxidant mechanism. This was based on the findings that BCL-2 expression can protect cells against oxidant stress and can inhibit the generation of reactive oxidant intermediates (ROIs) and/or their tissue destructive effects in conjunction with its anti-apoptotic influence (Kane et al, 1993; Hockenbery et al, 1993). An anti-oxidant role for BCL-2 would be consistent with a unifying hypothesis of apoptosis which alleges that intracellular reactive oxygen intermediates (ROls) are common mediators of this death process (Buttke and Sandstrom, 1994). However, more recent data suggest BCL-2 can protect against non-oxidative injury. This is supported by the findings that BCL-2 protects against apoptosis occurring in very low oxygen tension where ROI generation is minimal (Shimizu et al, 1995; Jacobson and Raff, 1995). Furthermore, BCL-2 is known to protect against apoptotic death induced by other stimuli which are not known to stimulate the generation of ROls, such as growth factor deprivation and c-myc expression (Nunez et al, 1990; Packham et al, 1996). One possible explanation for these divergent data is that BCL-2 blocks critical downstream events that are common to oxidative as well as non-oxidative triggers of apoptosis. However, if this were true, the ability of BCL-2 to inhibit intracellular ROI generation would be unexplained.

To further investigate this issue, we studied the effects of anti-oxidants and BCL-2 expression on tumor necrosis factor (TNF)- and etoposide (VP-16)-induced apoptosis as well as ROI generation and glutathione levels. TNF-induced cell death has been presented as supportive evidence of an important role for ROls in apoptosis (Hennet et al, 1993; Yamauchi et al, 1989; Schulze-Osthoff et al, 1992; Wong et al, 1989). However, TNF also induces cell death by nonapoptotic pathways (Laster et al, 1988) and it is possible that the non-apoptotic death is the one that is mediated by ROIs. Furthermore, the effects of the putative anti-oxidant BCL-2 on TNF cytotoxicity are inconsistent (Vanhaesebroeck et al, 1993; Fernandez et al, 1995; Vandenabeele et al, 1995; Itoh et al, 1993). One possible explanation for these inconsistencies is that whether TNF exerts its cytotoxicity by apoptotic versus non-apoptotic or oxidative versus non-oxidative mechanisms may be target dependent and, thus, whether BCL-2 prevents cell death may also be target dependent. To avoid this potential problem, we studied the effects of anti-oxidants and enforced BCL-2 expression in the same target cell, the L929 fibroblast.

We also used VP-16 as an inducer of apoptosis in this model because it is thought to be sensitive to BCL-2 mediated protection (Kamesaki et al, 1993; Dole et al, 1994) and mediates death by non-oxidative pathways (Holm et al, 1989). Thus, at first glance, VP-16 seems a prototype for BCL-2-induced protection against nonoxidative injury. However, earlier literature indicates that VP-16 may generate intracellular ROls (Mans et al, 1990; 
Haim et al, 1986) and the role of these ROls in VP-16 apoptosis has never been investigated. Our results show that TNF-induced apoptosis in this model is inhibited by antioxidants but not affected by BCL-2 expression. In contrast, VP-16-induced apoptosis of the same target is inhibited by BCL-2 but not by anti-oxidants. However, BCL2 exerted anti-oxidant effects in VP-16-treated cells. These results suggest that $\mathrm{BCL}-2$ can curtail $\mathrm{ROI}$ generation but argue against the hypothesis that these anti-oxidant effects are crucial to its protection against apoptosis.

\section{Results}

\section{TNF and VP-16 induce apoptotic death in L929 target cells}

As we have previously described (Fady et al, 1995), the death of L929 cells exposed to TNF is associated with the characteristic morphology of apoptosis and endonucleolytic cleavage of target cell DNA (Figure 1). These defining apoptotic changes were initiated approximately $8-12 \mathrm{~h}$ after treatment (Figure 1 and Mans et al, 1990), at a time when only minimal cytotoxicity was present $(26 \pm 3 \%$ for $1.2 \times 10^{4} \mathrm{pM} ; 12 \pm 3 \%$ for $6 \times 10^{3} \mathrm{pM}$ at $12 \mathrm{~h}$ ). They then increased over time to become maximal at $24 \mathrm{~h}$ of incubation. Death of the same target cells following incubation with VP-16 was associated with the same morphological abnormalities (not shown) and characteristic ladder-like DNA fragmentation (Figure 1). However, apoptosis was related to VP-16 concentration as shown in Figure 1. It was consistently detected in cultures treated with concentrations of VP-16>200 $\mu \mathrm{M}$. Although concentrations between 50 and $200 \mu \mathrm{M}$ often resulted in a cytostatic effect, they never induced endonucleolytic cleavage of DNA. DNA ladder formation in VP-16-treated targets was also first detected at approximately $8-12 \mathrm{~h}$ of culture and was optimal by $24 \mathrm{~h}$.

\section{Enforced expression of BCL-2 protects L929 cells against VP-16 but has no effect on TNF-treated targets}

L929 targets were transfected with the human BCL-2 gene or the empty vector (neo control) and then tested for sensitivity to TNF and VP-16. Efficient expression was achieved and confirmed by Western blotting. Transfected cells were not altered from parental cells in their morphology or doubling times (not shown). As shown in Figure 2, cytotoxicity induced by TNF after a $24 \mathrm{~h}$ exposure was unaffected by enhanced expression of BCL-2. When this assay was performed after only an $8 \mathrm{~h}$ exposure, the modest cytotoxicity of TNF $(20 \%$ from $1.2 \times 10^{4} \mathrm{pM}$ TNF) was similarly unaltered in BCL-2expressing cells (18\% cytotoxicity). In contrast, cytotoxicity induced by VP-16 used in concentrations below $400 \mu \mathrm{M}$ was significantly curtailed in BCL-2-expressing targets (Figure 2). Protection was not detected in target cells challenged with VP-16 concentrations of $400 \mu \mathrm{M}$ or
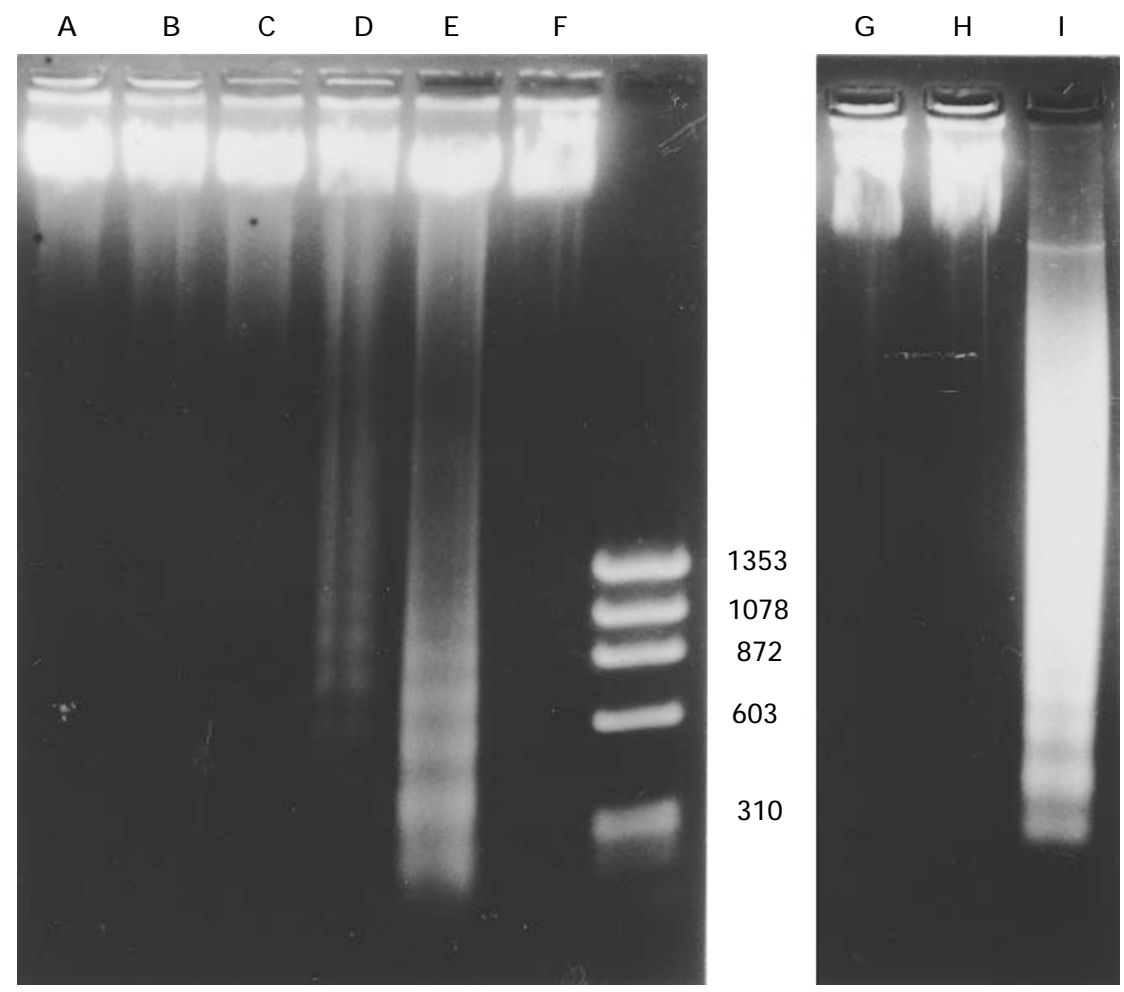

Figure 1 TNF and VP-16 induce endonucleosomal DNA fragmentation. DNA was isolated from L929 cells incubated with media for $24 \mathrm{~h}$ (control, lane F) or TNF $\left(6 \times 10^{3} \mathrm{pM}\right.$ ) for 4 (lane A), 6 (lane B), 8 (lane C), 12 (lane D) or $24 \mathrm{~h}$ (lane E) or VP-16 for $12 \mathrm{~h}$ at a concentration of $50 \mu \mathrm{M}$ (lane G), $100 \mu \mathrm{M}$ (lane H) or $250 \mu \mathrm{M}$ (lane I). Locations in the gel of DNA size standards shown are indicated in base pairs. This experiment was repeated three times with identical results. 
greater. Figure 3 demonstrates that BCL-2-mediated protection against $250 \mu \mathrm{M}$ VP-16 was seen as a delay in cytotoxicity rather than a complete inhibiton. Morphologic examination of Giemsa-stained cytosmears confirmed that apoptotic changes caused by VP-16 was diminished in BCL-2 expressing cells. After $12 \mathrm{~h}$ incubation with VP-16, examination of neo control targets demonstrated $33 \%$ of the cells were apoptotic whereas only $15 \%$ of similarly treated BCL-2-expressing targets were apoptotic. Further evidence that the transfected BCL-2 gene was functional was demonstrated when the transfected L929 cells were found to be relatively resistant to apoptosis induced by low concentrations of hydrogen peroxide (Gardner et al, 1997). Figure 4 demonstrates that BCL-2-induced protection against VP-16 was associated with a decrease in endonucleosomal DNA fragmentation.
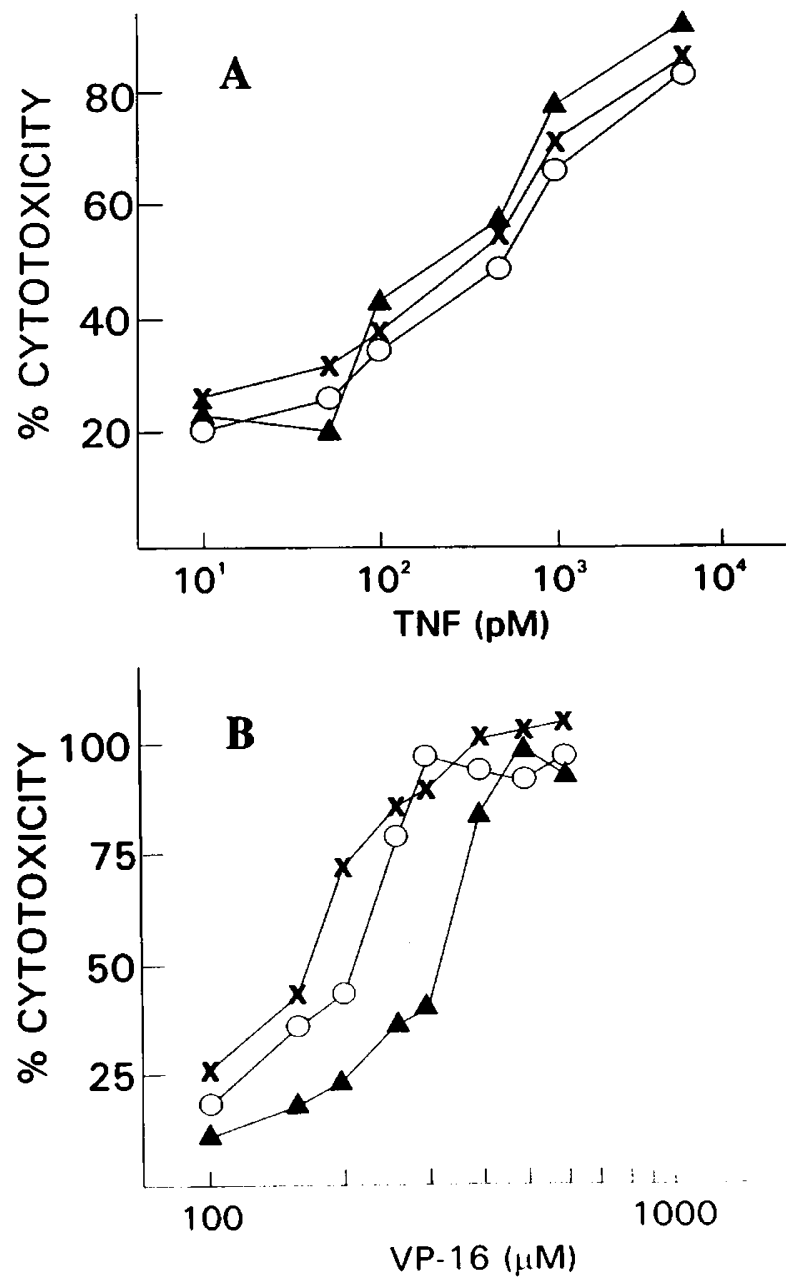

Figure 2 Effect of BCL-2 expression on TNF and VP-16 sensitivity. Parental L929 (O—— O), neo control L929 (X- - X) or BCL-2-expressing L929 cells $(\boldsymbol{\Delta}-\boldsymbol{\Delta})$ incubated with increasing concentrations of TNF for $24 \mathrm{~h}$ or VP-16 for $16 \mathrm{~h}$ and cytotoxicity assessed. Results are means of three separate experiments. The standard deviations (SDs) were $<10 \%$ of the means in all cases. Cytotoxicity induced by TNF was not significantly different among the three targets. Cytotoxicity to BCL-2-expressing cells was significantly below that to parental and neo control cells for VP-16 concentrations of 250 and $300 \mu \mathrm{M}$.

\section{Antioxidants inhibit TNF-induced apoptosis but not VP-16-induced apoptosis in L929 cells}

We utilized desferrioxamine, butylated hydroxyanisol (BHA) and $\mathrm{N}$-acetyl cysteine (NAC) as anti-oxidants to test whether

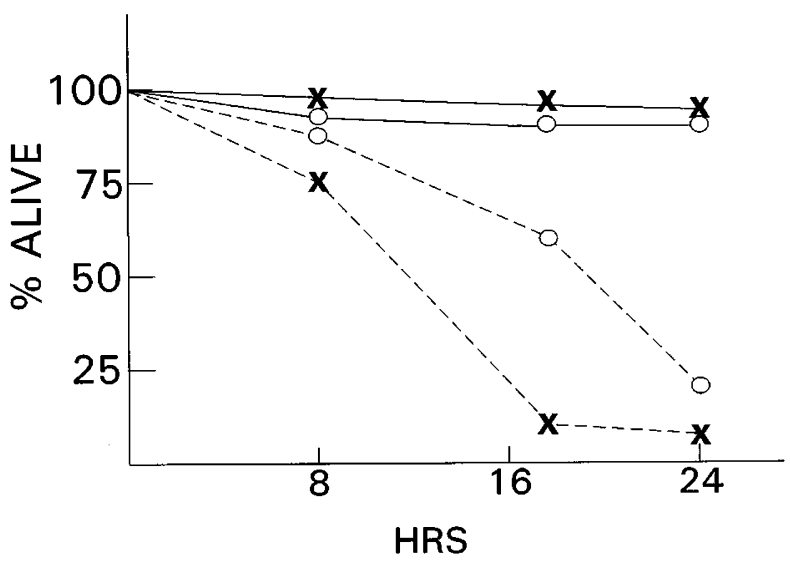

Figure 3 BCL-2 delays cytotoxicity induced by VP-16. Neo control targets cultured in media (X-X) or $250 \mu \mathrm{M}$ VP-16 $(\mathrm{X}-\mathrm{-}-\mathrm{X})$ for varying durations and compared to $\mathrm{BCL}-2$-expressing transfected cells cultured in media $(\mathrm{O}-\mathrm{O})$ or $250 \mu \mathrm{M}$ VP-16 (O- - - $)$ ). Viability determined by trypan blue exclusion. Results are means of quadruplicate samples. The SDs were $<5 \%$ of the means. The experiment was repeated $\times 1$ with identical results.

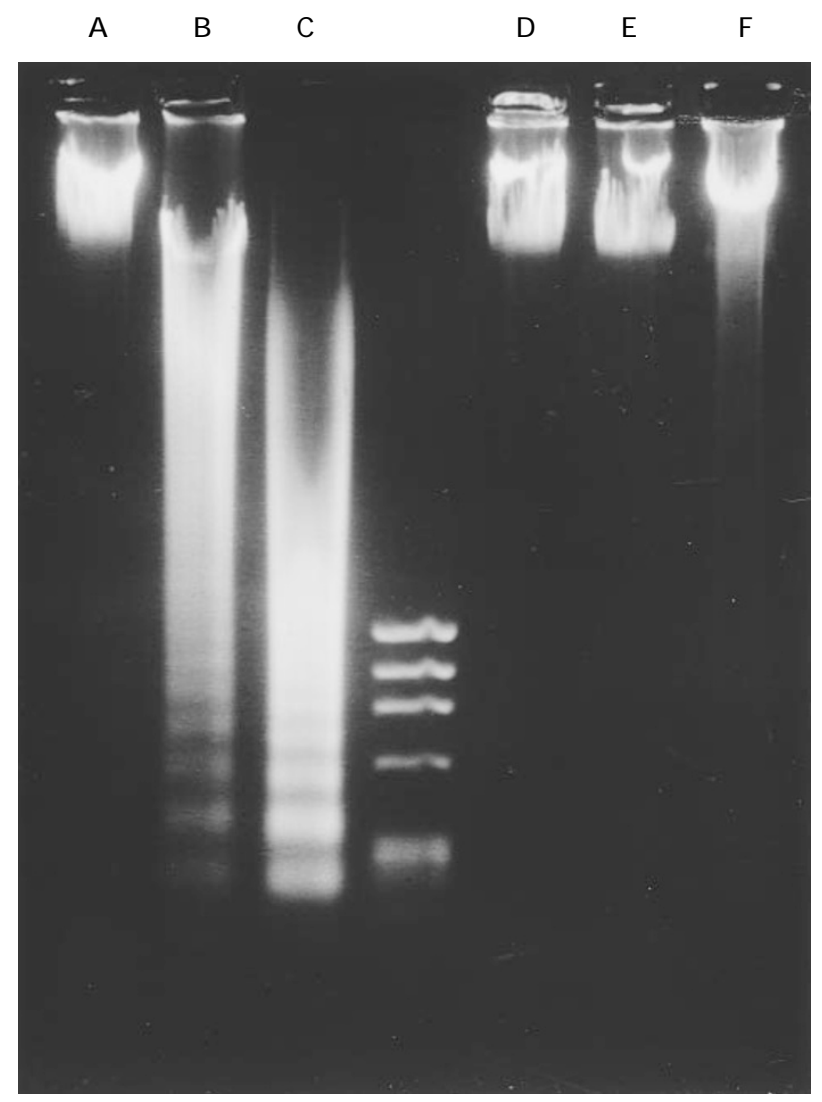

Figure 4 BCL-2 inhibits VP-16-induced DNA fragmentation. DNA isolated from neo-control cells $(\mathbf{A}-\mathbf{C})$ or BCL-2-transfected cells $(\mathbf{D}-\mathbf{F})$ cultured in media for $24 \mathrm{~h}$ (lanes $\mathbf{A}$ and $\mathbf{D}$ ) or VP-16 $(300 \mu \mathrm{M})$ for 12 (lanes $\mathbf{B}$ and $\mathbf{E})$ or 24 (lanes $\mathbf{C}$ and $\mathbf{F}$ ) $\mathrm{h}$. 
TNF- or VP-16-induced apoptotic death was mediated by ROls. These agents are unrelated and function as antioxidants through completely different mechanisms. Desferrioxamine is an iron chelator which suppresses hydroxyl radical formation by the Fenton reaction, $\mathrm{BHA}$ is a non-specific oxyradical scavenger and NAC, after uptake and deacylation, is converted to glutathione where it functions as a redox buffer and ROI scavenger. The anti-oxidant inhibitors were used in the highest concentrations possible that were not cytotoxic by themselves. Targets were exposed to desferrioxamine or NAC overnight prior to addition of VP-16 or TNF. Experiments with $\mathrm{BHA}$ were performed as co-cultures where $\mathrm{BHA}$ was added together with TNF or VP-16. All three anti-oxidant reagents significantly protected L929 targets against TNF-induced cytotoxicity in a concentration-dependent fashion (Figure 5). In general, BHA and NAC were more effective as inhibitors when compared to desferrioxamine. In addition, TNF-induced ladder-like DNA fragmentation was reduced by these agents (Figure 6). BHA and NAC were once again more effective with a complete prevention of any detectable DNA fragmentation while desferrioxamine only modestly inhibited ladder formation. In contrast to these results, these anti-oxidant inhibitors had no effect whatsoever on VP-16-induced cytotoxicity when used at the same concentrations. The ID50s for VP-16 in cultures exposed for $24 \mathrm{~h}$ were $270 \mu \mathrm{M}$ in control VP-16treated cells, $230-255 \mu \mathrm{M}$ in cultures containing $50-200 \mu \mathrm{M}$ of desferrioxamine, $250-280 \mu \mathrm{M}$ in cells co-cultured with $10-$ $200 \mu \mathrm{M}$ BHA and $260-275 \mu \mathrm{M}$ in cultures exposed to $25-$ $50 \mu \mathrm{M}$ of NAC. A similar lack of effect of these inhibitors on VP. 16 cytotoxicity was seen when the assay was performed after only $8 \mathrm{~h}$ of incubation (not shown). As expected, the inhibitors also had no effect on VP-16-induced endonucleosomal fragmentation as well as morphologic changes characteristic of apoptosis (not shown).

\section{VP-16 induces oxidant generation which is inhibited by anti-oxidants and BCL-2 expression}

The DCF fluorescence assay was used to test whether VP-16 treatment induced the detectable generation of intracellular ROls. L929 targets exposed to $250 \mu \mathrm{M}$ VP-16 demonstrated a significant increase in DCF fluorescence which was time dependent (Figure 7). This was accompanied by a significant fall in the intracellular level of glutathione (Figure 8). The increase in DCF fluorescence was significantly inhibited by co-incubation with $200 \mu \mathrm{M}$ of BHA (Figure 7), confirming the anti-oxidant's ability to inhibit ROI generation induced by VP16. Interestingly, BCL-2 expression in transfected cells also curtailed the ability of VP-16 to induce ROI generation and deplete the level of cellular GSH (Figure 8).

We also attempted to use the DCF assay to monitor ROI generation in TNF-treated cells. However, we detected insignificant ROI generation in this assay (Figure 7). However, oxy-radical induced DNA injury was clearly detected by an ELISA assay utilizing an antibody (Zimmerman et al, 1989) specific for oxidant-mediated thymine glycol base modifications. The reactivity of the antibody with TNF-treated L929 DNA was specifically inhibited by pre-incubation with osmium tetroxide-treated L929 DNA but not by S1 endonuclease-treated L929 DNA.
As shown in Table 1, TNF treatment results in extremely rapid generation of DNA thymine glycols first detected as
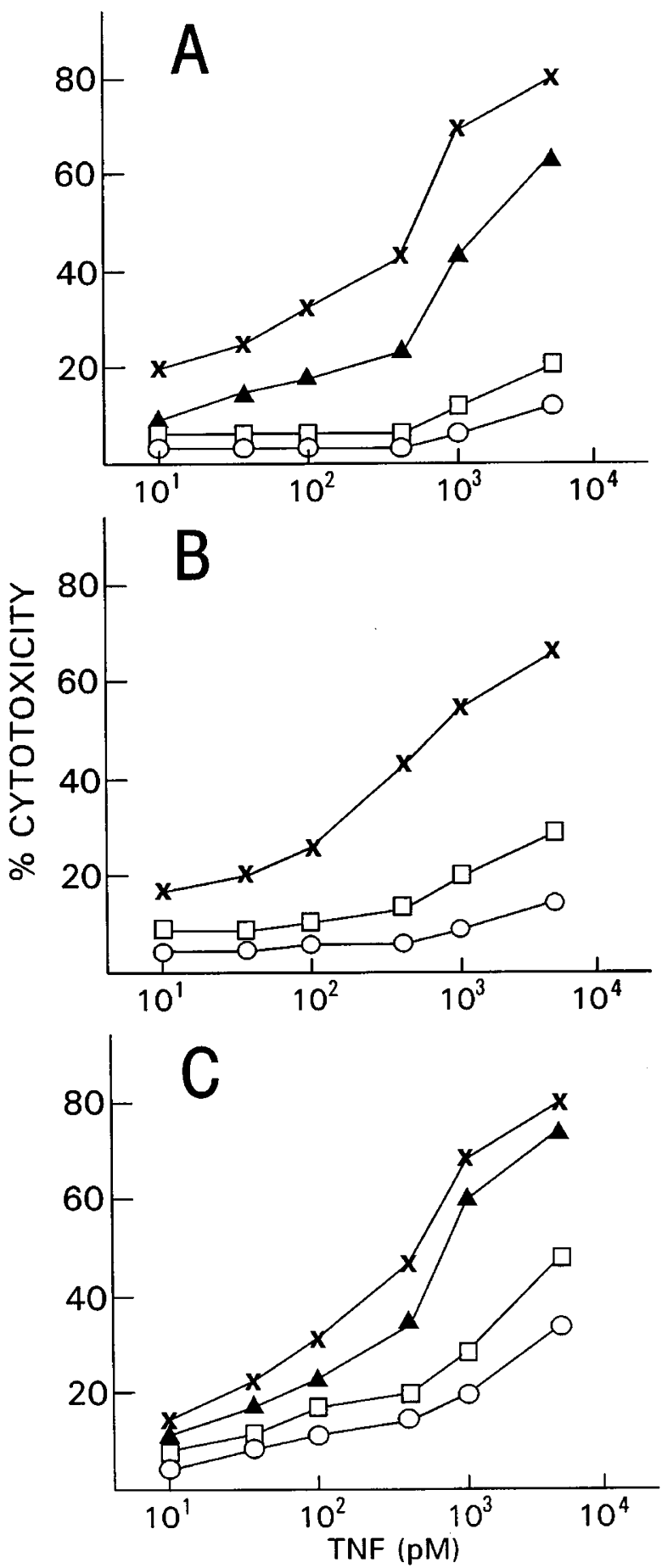

Figure 5 Anti-oxidants inhibit TNF cytotoxicity. L929 cells cultured for $24 \mathrm{~h}$ with increasing concentrations of TNF $\left(10^{1}-10^{4} \mathrm{pM}\right)+\mathrm{BHA}$ in $(\mathbf{A})(\mathrm{X}-\mathrm{X})$, control, $\mathrm{BHA}=0 ; \mathrm{O}-\mathrm{O}, \mathrm{BHA}=100 \mu \mathrm{M} ; \square-\square, \mathrm{BHA}=50 \mu \mathrm{M} ; \boldsymbol{\Delta}-\boldsymbol{\Delta}$, $\mathrm{BHA}=10 \mu \mathrm{M}), \mathrm{NAC}$ in $(\mathrm{B})(\mathrm{X}-\mathrm{X}$, control, NAC $=0 ; \bigcirc-O, N A C=50 \mathrm{mM}$; $\square-\square, N A C=25 \mathrm{mM})$ and desferrioxamine in $(\mathbf{C})(X-X$, control, des $=0$; $\bigcirc-— O$, des $=200 \mu \mathrm{M} ; \quad \square-\longrightarrow \square$, des $=100 \mu \mathrm{M} ; \boldsymbol{\Delta}-\longrightarrow \boldsymbol{\Delta}$, des $=50 \mu \mathrm{M}$ ). Cytotoxicity assesed by methylene blue assay. Results are means of four separate experiments for each inhibitor. SDs were $<10 \%$ of the means in all cases. 

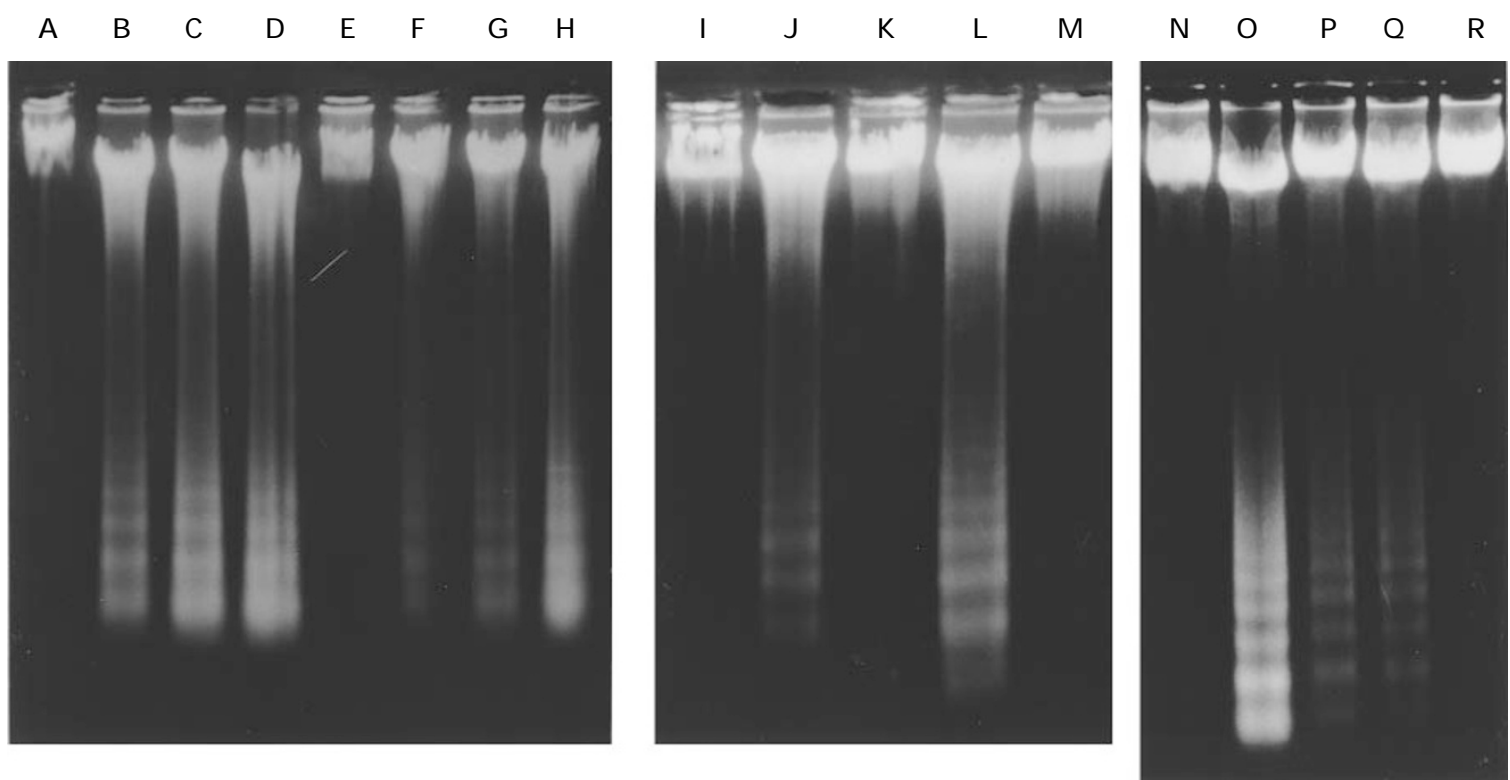

Figure 6 Effect of desferrioxamine $(\mathbf{A}-\mathbf{H})$, BHA $(\mathbf{I}-\mathbf{M}$ and NAC $(\mathbf{N}-\mathbf{R})$ on TNF-induced DNA fragmentation. In the first panel $(\mathbf{A}-\mathbf{H})$ cells incubated in media alone (lane $\mathbf{A}$ ), increasing concentrations of TNF alone $\left(6 \times 10^{2}, 1.2 \times 10^{3}\right.$ and $6 \times 10^{3} \mathrm{pM}$, lanes $\mathbf{B}, \mathbf{C}$ and $\mathbf{D}$ respectively), desferrioxamine alone $(200 \mu \mathrm{M}$, lane $\mathbf{E})$ or desferrioxamine+TNF $\left(6 \times 10^{2}, 1,2 \times 10^{3}\right.$ and $6 \times 10^{3} \mathrm{pM}$, lanes $\left.\mathbf{F}-\mathbf{H}\right)$. In the middle panel, cells incubated in media (lane I), TNF alone $\left(6 \times 10^{2}\right.$ and $6 \times 10^{3} \mathrm{pM}$, lanes $\mathbf{J}$ and $\mathbf{L})$ or the combination of BHA $\left(200 \mu \mathrm{M}\right.$ and TNF $\left(6 \times 10^{2}\right.$ and $6 \times 10^{3} \mathrm{pM}$, lanes $\mathbf{K}$ and $\left.\mathbf{M}\right)$. In the third panel, cells incubated in media alone (lane $\left.\mathbf{N}\right)$, TNF alone $\left(6 \times 10^{3}\right.$ and $6 \times 10^{2} \mathrm{pM}$, lanes $\mathbf{O}$ and $\left.\mathbf{Q}\right)$ or the combination of NAC $(50 \mathrm{mM})$ and TNF $\left(6 \times 10^{3}\right.$ and $6 \times 10^{2} \mathrm{pM}$, lanes $\mathbf{P}$ and $\left.\mathbf{R}\right)$. All incubations for $20 \mathrm{~h}$. All experiments repeated once with identical results.

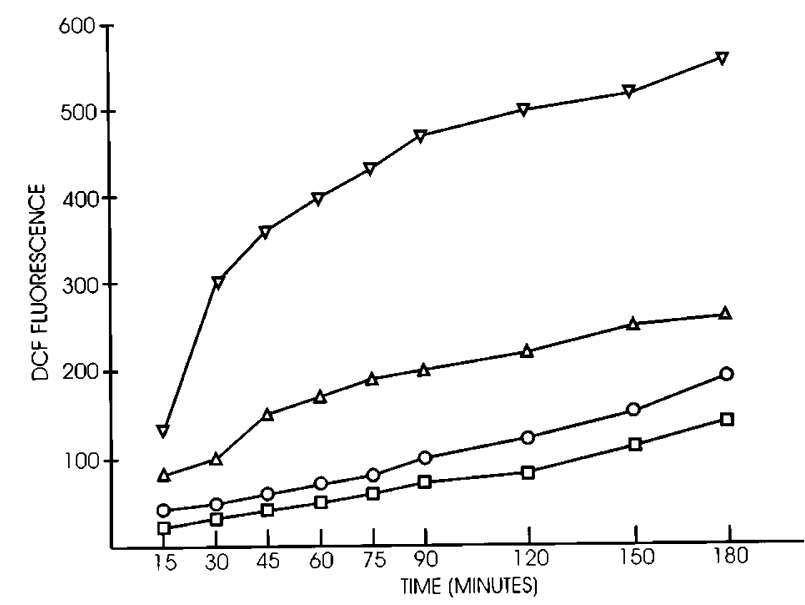

Figure 7 Intracellular generation of ROIs in L929 cells. DCF fluorescence measured over 180 minutes in L929 cells incubated alone $(\square)$, in $6 \times 10^{3} \mathrm{pM}$ TNF $(\bigcirc)$, in $250 \mu \mathrm{M}$ VP-16 $(\nabla)$ or $250 \mu \mathrm{M}$ VP-16 $+200 \mu \mathrm{M} \mathrm{BHA}(\triangle)$. Fluorescence was normalized to cell numbers as determined in Materials and Methods. Each point represents the mean of triplicate wells. The standard errors were all $<5 \%$ of the mean values. This experiment was repeated three times with similar results.

early as $2 \mathrm{~h}$ after treatment (in agreement with a previous report; Zimmerman et al, 1989). Desferrioxamine, BHA and NAC were all capable of preventing TNF-induced thymine glycol modification and the concentrations of these inhibitors that were effective correlated with the concentrations effective in protecting against TNF cytotoxicity (Table 2). A TNF-induced oxidative stress was also suggested by results of the GSH assay. TNF at $6 \times 10^{2} \mathrm{pM}$ (for $2 \mathrm{~h}$ )

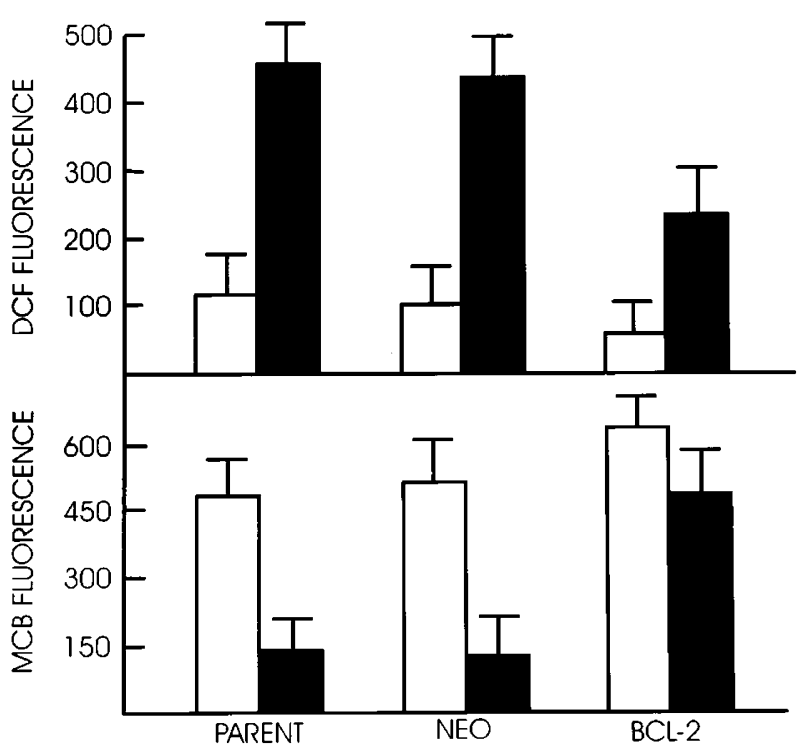

Figure 8 Effect of VP-16 on DCF fluorescence and GSH levels in BCL-2transfected cells. Parent non-transfected, neo-control transfected (empty vector) or BCL-2-transfected L929 cells were assayed for ROI generation by DCF fluorescence (following $2 \mathrm{~h}$ incubation without (open bars) or with VP-16, $250 \mu \mathrm{M}$ (darkened bars)) and for glutathione content by MCB fluorescence (open bars=no VP-16; darkened bars=VP-16, $250 \mu \mathrm{M}$ ). DCF and MCB fluorescence normalized for cell numbers. Values are means $\pm S D$ for three separate experiments. The increase in DCF fluorescence induced by VP-16 in $\mathrm{BCL}$-2-transfected cells is significantly less than in parental or neo-control cells. The decrease in MCB fluorescence induced by VP-16 in BCL-2transfected cells is significantly less than in parental or neo-control cells.

decreased the MCB fluorescence of L929 cells from 400 to 225 (mean of three separate experiments). Interestingly, 
enforced BCL-2 expression in the transfected line had no effect on the ability of TNF to reduce GSH levels (MCB fluorescence decreased from 450 to 200 following a $2 \mathrm{~h}$ exposure to TNF).

\section{Discussion}

The results of the current study do not support the hypothesis that BCL-2 functions as an anti-oxidant to inhibit apoptosis. First, TNF induced apoptotic death of L929 targets, which was very sensitive to marked inhibition by co-incubation with antioxidant agents, was completely resistant to regulatory control by enforced expression of BCL-2. Second, VP-16-induced apoptotic death of the same targets was significantly delayed by BCL-2 expression but was completely resistant to the same anti-oxidant drugs that curtailed TNF apoptosis. Although VP-16 stimulated ROI generation and BCL-2induced protection was associated with a diminished $\mathrm{ROI}$ generation, the fact that the anti-oxidant BHA, which depressed ROI generation equally (compare Figures 7 to 8), had no inhibitory effect on apoptosis, indicates that these alterations in oxidant production have no relevance to the degree of VP-16-induced cell death.

The results support previous investigations that also indicate BCL-2 can protect against non-oxidative injury. In studies by Shimizu et al (1995) and Jacobson and Raff (1995), BCL-2 was a successful protective influence in very low oxygen tensions when apoptosis was induced by staurosporine, anti-fas and growth factor depletion

Table 1 Generation of oxidative DNA damage in TNF-treated targets

\begin{tabular}{lcc}
\hline TNF & Treatment duration & Thymine glycols $/ \mathbf{1 0}^{\mathbf{5}}$ thymines \\
\hline- & $1 \mathrm{~h}$ & $<1$ \\
- & $2 \mathrm{~h}$ & $<1$ \\
- & $4 \mathrm{~h}$ & $<1$ \\
- & $6 \mathrm{~h}$ & $<1$ \\
+ & $1 \mathrm{~h}$ & 1.5 \\
+ & $2 \mathrm{~h}$ & 4.5 \\
+ & $4 \mathrm{~h}$ & 6.5 \\
+ & $6 \mathrm{~h}$ & 8 \\
\hline
\end{tabular}

L929 cells incubated with $\left(6 \times 10^{2}\right)$ or without TNF for various intervals after which DNA was extracted and assayed for thymine glycol formation in an ELISA. This experiment was repeated three more times with similar results.
(Jacobson and Raff, 1995) as well as hypoxia (Shimizu et al, 1995). Our results indicate that BCL-2-mediated protection against apoptosis induced by VP-16 is also independent of effects on ROls. Our model of VP-16induced apoptosis, however, was associated with concurrent $\mathrm{ROI}$ generation and glutathione depletion and, as such, allowed us to detect an anti-oxidant effect of BCL-2 which was not relevant to the oncoprotein's anti-apoptotic effect.

It is not clear from our data whether the anti-apoptotic and anti-oxidant effects of BCL-2 in our model are linked or dissociated. However, one possible unifying hypothesis is that BCL-2 suppresses apoptotic events that are upstream of ROI generation. Recent studies (Zamzami et al, 1996) suggest these events occur in mitochondria and represent opening of permeability transition (PT) pores, collapse of the mitochondrial transmembrane potential and release of a mitochondrial apoptotic protein into the cytosol. Furthermore, BCL-2 expression, with its specific localization to the outer mitochondrial membrane, prevents this sequence of events. Many different apoptotic signals appear to converge at the mitochondrial PT, including the inducers of apoptosis we used in the current study, TNF (Zamzami et al, 1996) and VP16 (Shimizu et al, 1996). The VP-16-induced collapse of the mitochondrial transmembrane potential is likely mediated by p53 activation (Marchetti et al, 1996). Interestingly, hyperproduction of ROls occurs secondarily to the loss of mitochondrial transmembrane potential and uncoupling of mitochondrial respiration. Thus, we hypothesize that a VP16-induced apoptotic signal stimulated opening of PT pores in L929 cells, release of an apoptotic mitochondrial protein which initiated an apoptotic cascade, and, only secondarily, hyperproduction of ROls. Enforced expression of BCL-2 in L929 cells protected against apoptosis by preventing release of the apoptotic mitochondrial protein. As a secondary result, the hyperproduction of ROls, which were not critical for apoptosis, was also down-regulated. This scenario could also explain the aforementioned results of Kane et al (1993) and Hockenbery et al (1993) where BCL-2 inhibited generation of peroxides and lipid peroxidation byproducts during protection against apoptosis.

In the current study, human TNF was used with murine fibroblast targets so that only the p55 receptor was engaged (Lewis et al, 1991). This engagement induced a cytotoxicity that was apoptotic in nature as endonucleoso-

Table 2 Inhibition of TNF-induced cytotoxicity and thymine glycol formation by desferrioxamine (des), BHA and NAC

\begin{tabular}{|c|c|c|c|c|c|c|c|}
\hline \multirow[b]{2}{*}{ Drug } & \multirow[b]{2}{*}{ Concentration } & \multicolumn{3}{|c|}{$\begin{array}{c}\text { TNF-induced } \\
\text { cytotoxicity (pM) }\end{array}$} & \multicolumn{3}{|c|}{$\begin{array}{c}\text { TNF-induced } \\
\text { thymine glycols } / 10^{5} \text { thymines }\end{array}$} \\
\hline & & $1.2 \times 10^{3}$ & $2.4 \times 10^{2}$ & $1.2 \times 10^{2}$ & $1.2 \times 10^{3}$ & $2.4 \times 10^{2}$ & $1.2 \times 10^{2}$ \\
\hline des & $200 \mu \mathrm{M}$ & $30^{\star}$ & $18^{\star}$ & $10^{\star}$ & $2^{*}$ & $1^{*}$ & $1^{*}$ \\
\hline des & $50 \mu \mathrm{M}$ & 68 & 59 & 34 & 7 & 5.5 & 2.5 \\
\hline $\mathrm{BHA}$ & $100 \mu \mathrm{M}$ & $10^{*}$ & $5^{\star}$ & $0^{*}$ & $1^{*}$ & $1^{*}$ & $1^{*}$ \\
\hline $\mathrm{BHA}$ & $10 \mu \mathrm{M}$ & $58^{*}$ & $37^{*}$ & $22^{*}$ & $5^{\star}$ & $3.5^{\star}$ & $2^{*}$ \\
\hline NAC & $5 \mathrm{mM}$ & $59^{*}$ & 46 & 33 & 8 & 4.5 & 3 \\
\hline
\end{tabular}

L929 cells exposed to TNF $\left(1.2 \times 10^{2}-1.2 \times 10^{3} \mathrm{pM}\right)$ in presence or absence of desferrioxamine (des), BHA and NAC. Cytotoxicity assayed after $20 \mathrm{~h}$ of incubation and thymine glycol formation after $4 \mathrm{~h}$. Data=values of three separate experiments. All standard deviations were less than $10 \%$ of the mean values. ${ }^{\star}$ Significantly different from control (no inhibitor, top line). 
mal degradation as well as the characteristic morphological alterations were present and preceded detected cytotoxicity. Although we could not detect ROI generation in the DCF assay, an ELISA assay utilizing an antibody specific for oxy-radical induced DNA injury served as an indicator of ROI generation. In addition, GSH levels decreased in TNFtreated cells confirming the development of oxidative stress. Effective concentrations of the anti-oxidants that inhibited the generation of oxy-radical induced thymine glycols also inhibited TNF cytotoxicity and endonucleosomal fragmentation. Thus, we are confident that ROI generation plays an important role in TNF-induced apoptotic death within this model. The DCF assay may not be sufficiently sensitive for TNF-induced ROI detection; it is mostly sensitive to hydroperoxides rather than superoxide anion. O'Donnell et al (1995) was also unable to detect TNF-stimulated ROIs in L929 cells using the DCF assay while other studies, which utilized the dihydrorhodamine (Shoji et al, 1995) or hydroethidine oxidation (Zamzami et al, 1996) assays were more successful. Packham et al (1996) has also shown the DCF assay to be relatively insensitive to the generation of intracellular ROIs that accompany apoptosis when compared to these other assays.

Recent studies have further elucidated two new pathways by which TNF can induce apoptosis. In one, following ligand binding, the death domain of the p55 TNFR1 recruits the other death domain-containing proteins TRADD, FADD and RIP (Hsu et al, 1995, 1996) and, from this complex, the death effector domain of FADD recruits the ICE-like protease MACH/FLICE (Boldin et al, 1996; Muzio et al, 1996). Theoretically, MACH/FLICE becomes activated (through yet unknown mechanisms) and the apoptotic effector protease cascade is initiated. In the second, a novel second messenger, ceramide, is produced subsequent to ligand binding and sphingomyelinase activation (Kolesnik and Golde, 1994). When applied to cells, exogenous ceramide induces apoptosis (Obeid et al, 1993), providing support for its role in TNFinduced apoptosis. These two new potential pathways of apoptosis must be added to previously described mechanisms that are activated subsequent to ligand binding and which experimental data supports their involvement in TNF-induced apoptosis. These include the activation of other second messengers like arachidonic acid metabolites and intracellular calcium (reviewed by Beyart and Fiers, 1994) as well as the above mentioned effect on the mitochondrial PT. The multitude of possible TNF-induced pathways of apoptosis provides a possible explanation for the variable effects of BCL-2 (Vanhaesebroeck, Fernanadez, Vandenable, Itoh). Due to its subcellular localization, BCL-2 is well suited to block TNF apoptotic signals and ICE-like protease activation mediated via effects on the mitochondrial PT. However, if the protease cascade is initiated by $\mathrm{MACH} / \mathrm{FLICE}$ when they are linked to p55 via FADD at the cell membrane or by a second messenger such as cytosolic phospholipase $\mathrm{A}_{2}\left(\mathrm{PLA}_{2}\right)$ (Voekel-Johnson et al, 1996), BCL-2 would be less effective. Although TNF may open PT in L929 cells, the lack of inhibitory effect of BCL-2 in our model indicates there must be other TNF-induced pathways in our cells, possibly related to protein recruitment to membrane p55 or PLA2 activation where ICE-like proteases are activated in a milieu protected from BCL-2.

It remains a challenge for investigators to integrate the newly discovered metabolic mechanism of TNF-induced apoptosis with its known oxygen or oxyradical dependence. The mechanism by which the anti-oxidant reagents we used inhibited cell death is still unclear but several possibilities can be considered. The first is that these anti-oxidants inhibited the generation of mitochondrial ROls and, thus, curtailed apoptosis. Although the initial TNFinduced opening of mitochondrial PT only leads secondarily to hyperproduction of ROls (Zamzami et al, 1995), increasing oxidant accumulation could provide a selfamplification loop as ROls themselves can further alter PT and disrupt the mitochondrial transmembrane potential (Zamzami et al, 1995, 1996). This may be the mechanism by which low concentrations of hydrogen peroxide (Gardner et al, 1997) or other oxidants induce apoptosis and might explain why mitochondrial BCL-2 expression can protect against this injury. Thus, it is theoretically possible that inhibition of mitochondrial-generated ROIs with antioxidants could significantly decrease an apoptotic stimulus. We consider this unlikely since, as explained above, we would have expected BCL-2 expression to also inhibit apoptosis if it was initiated at the mitochondrial PT. Furthermore, BCL-2 expression did not alter the decrease in GSH induced by TNF, indicating this oxidative stress did not likely result from mitochondria. A second possibility is that TNF-induced ROls that mediate apoptosis were generated in extramitochondrial sites. For example, cytosolic $\mathrm{PLA}_{2}$ is necessary for apoptosis of melanoma cells induced by TNF plus metabolic inhibitors (Voekel-Johnson et al, 1996), TNF can activate $\mathrm{PLA}_{2}$ in $\mathrm{L} 929$ cells (Hayakawa et al, 1993) and there is some support that ROI byproducts of the $\mathrm{PLA}_{2}$-arachidonate pathway can mediate TNF cytotoxicity (Hayakawa et al, 1993; Matthews et al, 1987). A third possibility is that ROIs are not involved directly in TNFinduced apoptosis but that the redox state of the cell significantly regulates other apoptotic pathways. The intracellular redox state is buffered by thiol-type reducing molecules of which glutathione is the principal agent. The two most effective inhibitors in our study, NAC and BHA, would be expected to enhance this buffering capacity, NAC by its conversion to GSH following deacylation, and $\mathrm{BHA}$, by its scavenging of ROls and prevention of ROl-induced GSH oxidation and loss by the cell. In addition, an unrelated reducing agent, adult T-cell leukemia-derived factor (Matsuda et al, 1991), which also functions as a cytoplasmic reducing agent, protects against TNF. The redox potential might regulate inherently non-oxidative apoptotic pathways through its effect on signal-transducing protein tyrosine kinases and/or protein tyrosine phosphatases. For example, protein tyrosine phosphatases have a reactive cysteine residue at their catalytic sites which must be in the reduced form for activity (Staal et al, 1994). Further support for this theory comes from the finding that TNF stimulates extensive tyrosine phosphorylation in cells only if GSH has been depleted (Staal et al, 1994) and 
protein kinase activity seems to be important for p55 signalling of apoptosis (Grell et al, 1994). Since alteration of the thiol buffering capacity would affect the cell's redox state by regulating the small amount of endogenous ROls continuously produced even in the absence of an enhanced oxidative stress, this hypothesis could also explain several studies where antioxidant GSH/thiol-enhancing reagents can protect against apoptosis even in the absence of ROI production by the apoptotic signal in question (Packham et al, 1996; Hockenbery et al, 1993; Chiba et al, 1996; O'Donnell et al, 1995). Further support for this hypothesis comes from the effects of dithiothreitol and cycloheximide. The former sulfhydryl agent, which protects enzymes against redox-induced transition of sulfhydryl groups, protects against TNF cytotoxicity (Shoji et al, 1995). The latter inhibitor of protein synthesis significantly reduces levels of intracellular GSH (Chiba et al, 1996) and this reduced buffering capacity may play a role in the ability of cycloheximide to enhance TNF cytotoxicity.

In summary, the results of this study demonstrate that, although BCL-2 expression can decrease ROI generation within cells it is simultaneously protecting from apoptosis, its protective effects are not due to these anti-oxidant properties. The important role of ROls in the distinct TNF-induced pathways that result in apoptosis remain to be clarified.

\section{Materials and Methods}

\section{Target cell}

The murine L929 fibroblast cell line was obtained from the American Type Culture Collection and maintained in RPMI medium supplemented with $10 \%$ fetal calf serum, glutamine and antibiotics.

\section{Reagents}

Recombinant human TNF was a gift from Genentech Inc. (South San Francisco, CA). The specific activity was $6.27 \times 10^{7} \mathrm{U} / \mathrm{mg}$ protein. All other reagents were purchased from Sigma Chemical Co. (St. Louis, MO) unless otherwise designated.

\section{Cytotoxicity assay}

The methylene blue cytotoxicity assay was performed as previously described (Fady et al, 1995). Briefly, $10^{4}$ cells in $100 \mu \mathrm{l}$ were dispensed into a 96 well microtitre plate, allowed to adhere overnight and then exposed to serial dilutions of TNF or VP-16 in an additional $100 \mu \mathrm{l}$. After varying intervals, media and dead cells were removed, viable cells were fixed in $95 \%$ ethanol and then stained with $1 \%$ methylene blue. Following washing of plates, blue dye was solubilized in $100 \mu \mathrm{l} \mathrm{HCl}(1 \mathrm{M})$ and optical density read at $630 \mathrm{~nm}$. Groups were run in quadruplicate and the standard deviation (SD) of replicates was always $<10 \%$ of the mean. Percent cytotoxicity was determined as $100 \times$ (ODcontrol-ODexp/ODcontrol). The concentration of TNF or VP-16 inducing $50 \%$ inhibition of cell survival (ID50) was extrapolated from results of the cytotoxicity assay.

\section{Electrophoresis of DNA}

As previously described (Fady et al, 1995) cells were lysed in $10 \mathrm{mM}$ Tris- $\mathrm{HCl}(\mathrm{pH} 7.5), 100 \mathrm{mM}$ EDTA, $0.5 \%$ SDS and $100 \mu \mathrm{g} / \mathrm{ml}$ of proteinase $\mathrm{K}$ for $18 \mathrm{~h}$ at $37^{\circ}$. DNA was then extracted twice with phenol, $\mathrm{PCl}$ and chloroform, precipitated in ethanol, centrifuged (30 min at $10000 \mathrm{~g}$ ) and resuspended in TE buffer containing $100 \mu \mathrm{g} /$ $\mathrm{ml}$ of RNase for $1 \mathrm{~h}$ at $37^{\circ}$. Following one more extraction in phenol, $\mathrm{PCl}$ and chloroform and precipitation on $70 \%$ ethanol, DNA was resuspended in TE buffer and $10 \mu \mathrm{g}$ DNA per lane was electrophoresed in a $1 \%$ agarose gel for $2 \mathrm{~h}$ at $45 \mathrm{~V}$. The gels were visualized with ethidium bromide.

\section{BCL-2 transfection}

The full length BCL-2 CDNA was a gift from Dr Dale Bredesen, UCLA. It was subcloned into the pcDNA3 expression vector (Invitrogene, San Diego, CA) with EcoRI and Xbal sites. Plasmids for transfection were purified with Maxprep kit (Promega, Madison, WI). Transfection was performed according to manufacturer's instruction. Briefly, L929 cells were trypsinized and seeded at $10^{6}$ cells per $100 \mathrm{~mm}$ dish $24 \mathrm{~h}$ prior to transfection. Plasmid and Dotap solution (Boehringer, Hague Road, IN) were diluted to $0.05 \mu \mathrm{g} / \mathrm{ml}$ and $1 \mu \mathrm{g} / \mathrm{ml}$ respectively with $200 \mathrm{mM}$ HEPES buffer, $\mathrm{pH}$ 7.4. Diluted plasmid DNA and Dotap solution were mixed at a ratio of $1: 2$ and kept at room temperature for $15 \mathrm{~min}$. One hundred and fifty $\mu \mathrm{l}$ of the above mixed solution was added to $10 \mathrm{ml}$ of complete media for each sample. After mixing gently, it was used immediately to replace the culture media in each dish. After $10 \mathrm{~h}$ exposure, the transfection media was removed and cells were re-fed with fresh media for another $24 \mathrm{~h}$. At that point, transfected cells were selected in G418 (GIBCO BRL, Grand Island, NY).

\section{Assay for generation of intracellular ROls}

Intracellular ROI generation was assessed by a previously described assay (Sarafian et al, 1994) that primarily measures hydrogen peroxide and hydroxyl radical. Briefly, targets in 48 well plates were washed $\times 2$ with $0.5 \mathrm{ml}$ buffer $(25 \mathrm{mM}$ HEPES, pH 7.4, $125 \mathrm{mM} \mathrm{NaCl}$, $5 \mathrm{mM} \mathrm{KCl}, 1.2 \mathrm{mM} \mathrm{KH}_{2} \mathrm{PO}_{4}, 5 \mathrm{mM} \mathrm{NaCO}, 6 \mathrm{mM}$ glucose, $1.2 \mathrm{mM}$ $\mathrm{MgSO}_{4}$ and $1.0 \mathrm{mM} \mathrm{CaCl}_{2}$ ) and loaded with $40 \mu \mathrm{M} \mathrm{2,7} \mathrm{dichloro-}$ fluorescin diacetate (DCF) in $0.5 \mathrm{ml}$ buffer. After incubating in the dark for $20 \mathrm{~min}$ at room temperature, cells were washed $\times 2$, sealed and kept in the dark until reading. DCF fluorescence was measured over a $3 \mathrm{~h}$ time period at $30 \mathrm{~min}$ intervals with a cytofluor 2300 plate reader set at $E A=485$ and $E M=530$. The assay was run with three wells/group and mean fluorescence was calculated. Values were normalized to cell numbers based on maximum propidium iodide fluorescence values in the presence of $160 \mu \mathrm{M}$ digitonin.

\section{Assay for intracellular glutathione (GSH) levels}

As previously described (Sarafian et al, 1994), GSH levels were assayed with the fluorescent reagent monochlorobimane (MCB) and cytofluor 2300 set at $E x=395, E m=460$. Following DCF measurements, buffer was removed and $250 \mu \mathrm{l}$ of fresh buffer containing $40 \mu \mathrm{M} \mathrm{MCB}$ was added. Fluorescence was measured after $15 \mathrm{~min}$ and values normalized to cell numbers as above.

\section{Thymine glycol determination}

As previously described (Zimmerman et al, 1989), cell pellets were lysed in $10 \mathrm{mM}$ Tris- $\mathrm{HCl}: 1 \mathrm{mM}$ EDTA $(\mathrm{pH} 8.0): 0.1 \%$ sodium dodecyl sulfate and incubated with RNase $\mathrm{A}(0.1 \mathrm{mg} / \mathrm{ml})$ for $1 \mathrm{~h}$ and proteinase $\mathrm{K}(0.1 \mathrm{mg} / \mathrm{ml})$ for $1 \mathrm{~h}$. The DNA was purified by extractions with phenol:chloroform:isoamylalcohol $(24: 24: 1)$, and chloroform:isoamylalcohol (24:1), followed by precipitation in $70 \%$ alcohol. 
The DNA was dissolved in PBS and concentration and purity determined spectrophotometrically. The ELISA for quantification of thymine glycols in DNA was performed using the monoclonal antibody GB10/C5, a generous gift from Dr S.A. Leadon.

\section{Western blot determination}

Transfected cells were washed once with cold PBS. Five million cells were lysed in $50 \mu$ of lysis buffer ( $1 \%$ triton $\times 100,0.5 \%$ NP40, $10 \mathrm{mM}$ Tris pH 7.4, $150 \mathrm{mM} \mathrm{NaCl}, 1 \mathrm{mM}$ EDTA, $1 \mathrm{mM}$ EGTA, $0.2 \mathrm{mM}$ $\mathrm{Na}_{3} \mathrm{VO}_{4}, 0.2 \mathrm{mM} \mathrm{NaF}$ and $0.2 \mathrm{mM} \mathrm{PMSF}$ ). Cell lysates were cleared at $14000 \mathrm{rpm}$ for $15 \mathrm{~min}$ at $4^{\circ} \mathrm{C}$. Twenty-five $\mu \mathrm{g}$ of protein from each sample was boiled for $5 \mathrm{~min}$ in $1 \times$ SDS gel-loading buffer $(125 \mathrm{mM}$ Tris, $\mathrm{pH} 6.8,5 \%$ glycerol, $2 \%$ SDS, $1 \%$ beta-mercaptoethanol and $0.006 \%$ bromophenol blue). Proteins were separated by $12.5 \%$ SDS PAGE and transferred onto PUDF membrane. The membrane was blocked $1 \mathrm{~h}$ at room temperature in 3\% BSA, $5 \%$ non-fat dried milk, $10 \mathrm{mM}$ Tris, $\mathrm{pH} 7.5,100 \mathrm{mM} \mathrm{NaCl}$ and $0.1 \%$ Tween 20). After four washes in TBS-T buffer, the membrane was incubated with $0.5 \mu \mathrm{g} / \mathrm{ml}$ rabbit anti-human BCL-2 antibody (kind gift from Dr John Reed, La Jolla, CA) for $1 \mathrm{~h}$. After four more washes, the membrane was overlayed with $1 \mu \mathrm{g} / \mathrm{ml}$ HRP-labelled goat anti-rabbit IgG antibody (Amersham) and the BCL-2 protein band was detected with an ECL system.

\section{Statistics}

Significant differences between groups was determined by the $t$-test using the Bonserroni correction for multiple comparisons.

\section{Acknowledgements}

The authors thank Dr SA Leadon for his gift of antibody GB 10/C5 and his help in setting up the ELISA for thymine glycol determination. The authors also thank Drs Dale Bredesen and John Reed for their generous gifts of BCL-2 cDNA and anti-human BCL-2 antibody, respectively. This research was supported by research funds of the Veteran's Administration.

\section{References}

Beyaert R and Fiers W (1994) Molecular mechanisms of tumor necrosis factorinduced cytotoxicity. FEBS Lett. 340: 9-16

Boldin MP, Goncharov TM, Goltsev YV and Wallach D (1996) Involvement of MACH, a novel MORT1/FADD-interacting protease in FAS/APO-1 and TNF receptorinduced cell death. Cell 85: 803-815

Buttke TM and Sandstrom PE (1994) Oxidative stress as a mediator of apoptosis. Immunology Today 15: 7-10

Chiba T, Takahashi S, Sato N, Ishii S and KikuchiK(1996) FAS mediated apoptosis is modulated by intracellular glutathione in human T cells. Eur. J. Immunol. 26 $1164-1169$

Dole M, Nunez G, Merchant AK, Maybaum J, Rode CK, Bloch J and Castle VP (1994) BCL-2 inhibits chemotherapy-induced apoptosis in neuroblastome. Cancer Research 54: 3253-3259

Fady C, Gardner A, Jacoby F, Briskin K, Tu Y, Schmid I and Lichtenstein A (1995) Atypical apoptotic cell death induced in L929 targets by exposure to tumor necrosis factor. Journal of Interferon and Cytokine Research 15: 71-80

Fernandez A, Fosdick LJ, Marin MC, Diaz C, McDonnell TJ, Ananthaswamy HN and McConkey DJ (1995) Differential regulation of endogenous endonuclease activation in isolated murine fibroblast nuclei by ras and BCL-2. Oncogene 10 : $769-774$

Gardner A, Xu F, Fady C, Jacoby F, Duffey D, Tu Y and Lichtenstein A (1997) Apoptotic versus non-apoptotic cytotoxicity induced by hydrogen peroxide. Free Rad. Biol. \& Med. (in press)
Grell M, Zimmerman G, Hulser D, Pfizenmaier K and Scheurich P (1994) TNF receptors TR60 and TR80 can mediate apoptosis via induction of distinct signal pathways. Journal of Immunology 153: 1963-1972

Haim N, Roman J, Nemec J and Sinha BK (1986) Peroxidative free radical formation and O-demethylation of etoposide and teniposide. Biochemical and Biophysical Research Communications 135: 215-220

Hayakawa M, Ishida N, Takauchi K, Shibamoto S, Hori T, Oku N, Ito F and Tsujimoto M (1993) Arachidonic acid-selective cytosolic phospholipase A2 is crucial in the cytotoxic action of TNF. J. Biol. Chem. 268: 11290-11298

Hennet T, Richter C and Peterhans E (1993) Tumor necrosis factor induces superoxide anion generation in mitochondria of L929 cells. Biochemical Journal 289: $587-592$

Hockenbery DM, Oltvai ZN, Yin X, Milliman CL and Korsmeyer SJ (1993) BCL2 functions in an antioxidant pathway to prevent apoptosis. Cell 75: $241-$ 251

Holm C, Covey JM, Kerrigan D and Pommier Y (1989) Differential requirement of DNA replication for the cytotoxicity of DNA topoisomerase I and II inhibitors in Chinese Hamster DC3F cells. Cancer Research 49: 6365-6368

Hsu H, Xiong J and Goeddel D (1995) The TNF-receptor 1-associated protein TRADD signals cell death and NF-kB activation. Cell 81: 495-504

Hsu H, Shu H, Pan M and Goeddel D (1996) TRADD-TRAF 2 and TRADD-FADD interactions define two distinct TNF receptor 1 signal transduction pathways. Cell 84: $299-308$

Itoh N, Tsujimoto Y and Nagata S (1993) Effect of BCL-2 on fas antigen-mediated cell death. Journal of Immunology 151: 621-627

Jacobson MD and Raff MC (1995) Programmed cell death and BCL-2 protection in very low oxygen. Nature 374: 814-816

Kamesaki S, Kamesaki H, Jorgensen TJ, Tanizawa A, Pommier $Y$ and Cossman J (1993) BCL-2 protein inhibits etoposide-induced apoptosis through its effects on events subsequent to topoisomerase II-induced DNA strand breaks and their repair. Cancer Research 53: 4251-4256

Kane DJ, Sarafian TA, Anton R, Hahn H, Gralla EB, Valentine JS, Ord T and Bredesen D (1993) BCL-2 inhibition of neural death: Decreased generation of reactive oxygen species. Science 262: 1274-1277

Kolesnick R and Golde D (1994) The sphingomyelin pathway in tumor necrosis factor and IL-1 signalling. Cell 77: $325-328$

Laster SM, Wood JG and Gooding LR (1988) Tumor necrosis factor can induce both apoptotic and necrotic forms of cell lysis. Journal of Immunology 14:2629-2634

Lewis M, Tartaglia L, Lee A, Bennett G, Rice G, Wong G, Chen E and Goeddel D (1991) Cloning and expressing of cDNAs for two distinct murine tumor necrosis factor receptors demonstrate one receptor is species specific. Proceedings of National Academy of Sciences 88: 2830-2836

Mans DRE, Retel J, Van Maanen JMS, Lafleur MVM, van Schaik MA, Pinedo HM and Lankelma J (1990) Role of the semi-quinone free radical of the anti-tumor agent etoposide in the inactivation of single- and double-stranded OX174 DNA. British Journal of Cancer 62: $54-60$

Marchetti P, Castedo M, Susin S, Zamzami N, Hirsch T, Macho A, Haeffner A, Hirsch $F$, Genskens M and Kroemer G (1996) Mitochondrial permeability transition is a central coordinating event of apoptosis. J. Exp. Medicine 184: 1155-1160

Matsuda M, Matsutani H, Nakamura H, Miyajima S, Yamauchi A, Yonehara S, Uchida A, Irimajiri K and Yodoi J (1991) Protective activity of adult T cell leukemiaderived factor against TNF cytotoxicity on U937 cells. J. Immunol. 147: $3837-$ 3843

Matthews N, Neale M, Jackson S and Stark J (1989) Tumor cell killing by TNF: Inhibition by anaerobic conditions, free radical scavengers and inhibitors of arachidonate metabolism. Immunology 62: 153-160

Muzio M, Chinnaiyan AM, Kischkel FC, O'Rourke K, Shevchenko A, Ni J, Scaffidi C, Bretz JD, Zhang M, Gentz R, Mann M, Krammer P and Dixit VM (1996) FLICE, a novel FADD-homologous ICE/CED-3-like protease, is recruited to CD95 deathinducing signal complex. Cell 85: 817-827

Nunez G, London L, Hockenbery D, Alexander M, Mckearn JP and Korsmeyer SJ (1990) Deregulated BCL-2 gene expression selectively prolongs survival of growth factor-deprived hemopoietic cell lines. Journal of Immunology 144: $3602-3610$

Obeid LM, Linardic CM, Karolak LA and Hannun YA (1993) Programmed cell death induced by ceramide. Science 259: $1769-1771$

O'Donnell VB, Spycher S and Azzi, A (1995) Involvement of oxidants and oxidantgenerating enzymes in TNF-mediated apoptosis: role for lipoxygenase pathway but not mitochondrial respiratory chain. Biochem. J. 310: 133-141 
Packham G, Ashmun RA and Cleveland JL (1996) Cytokines suppress apoptosis independent of increases in reactive oxygen levels. J. Immunol. 156: 27922800

Sarafian TA, Vartavarian L, Kane D, Bredesen D and Verity M (1994) BCL-2 expression decreases methyl mercury-induced free-radical generation and cell killing in a neural cell line. Toxicology Letters 74: 149-155

Schulze-Osthoff K, Bakker AC, Vanhaesebroeck B, Beyaert R, Jacob W and Fiers W (1992) Cytotoxic activity of tumor necrosis factor is mediated by early damage of mitochondrial functions. Journal of Biological Chemistry 267: 5317-5323

Shimizu S, Eguchi Y, Kosaka H, Kamiike W, Matsuda H and Tsujimoto Y (1995) Prevention of hypoxia-induced cell death by BCL-2 and BCL-X-L. Nature 374: $811-813$

Shimizu S, Eguchi Y, Kamiike W, Waguri S, Uchiyama Y, Matsuda Hand Tsujimoto Y (1996) BCL-2 blocks loss of mitochondrial membrane potential while ICE inhibitors act a different step during inhibition of death induced by respiratory chain inhibitors. Oncogene 13: 21-29

Shoji Y, Uedonon Y, Ishikura H, Takeyama N and Tanaka T (1995) DNA damage induced by TNF in L929 cells is mediated by mitochondrial oxyradical formation. Immunology 84: 543-548

Staal F, Anderson MT, Staal GE, Herzenberg LA, Gitler C and Herzenberg L (1994) Redox regulation of signal transduction: Tyrosine phosphorylation and calcium flux. Proc. Natl. Acad. Sci. 91: 3619-3622

Vandenabeele P, Declercq W, Vanhaesebroeck B, Grooten J and Fiers W (1995) Both TNF receptors are required for TNF-mediated induction of apoptosis in PC60 cells. Journal of Immunology 154: 2904-2913
Vanhaesebroeck B, Reed JC, De Valck D, Grooten J, Miyashita T, Tanaka S, Beyaert $R$, Van Roy F and Fiers W (1993) Effect of BCL-2 proto-oncogene expression on cellular sensitivity to tumor necrosis factor-mediated cytotoxicity. Oncogene 8 : $1075-1081$

Voekel-Johnson C, Thorne T and Laster SM (1996) Susceptibility to TNF in the presence of inhibitors of transcription or translation is dependent on the activity of cytosolic phospholipase A2 in human melanoma cells. J. Immunol. 156: 201 207

Wong G, Elwell J, Oberley L and Goeddel D (1989) Manganous superoxide dismutase is essential for cellular resistance to cytotoxicity of tumor necrosis factor. Cell 58: 923-932

Yamauchi N, Kuriyama H, Watanabe N, Neda H, Maeda M and Niitsu Y (1989) Intracellular hydroxyl radical production induced by recombinant human tumor necrosis factor and its implication in the killing of tumor cells in vitro. Cancer Research 49: 1671 - 1675

Zamzami N, Marchetti P, Castedo M, Zanin C, Vayssiere J-L, Petit PX and Kroemer G (1995) Reduction in mitochondrial membrane potential constitutes an early irreversible step in programmed lymphocyte death in vivo. J. Exp. Medicine 181: $1661-1672$

Zamzami N, Susin SA, Marchetti M, Hirsch T, Castedo M and Kroemer G (1996) Mitochondrial control of nuclear apoptosis. J. Exp. Medicine 183: 1533-1544

Zimmerman R, Chan A and Leadon SA (1989) Oxidative damage in murine tumor cells treated in vitro by recombinant human tumor necrosis factor. Cancer Research 49: $1644-1648$ 